\title{
United Nations Sustainable Development Goals 2030 and environmental sustainability: race against time
}

\author{
Naveen Kumar Arora ${ }^{1}$ - Isha Mishra² \\ Published online: 11 November 2019 \\ (c) Society for Environmental Sustainability 2019
}

United Nations Sustainable Development Goals (SDGs), established on September 15, 2015 entitled as "Transforming our world: the 2030 Agenda for Sustainable Development", are a follow up of Millennium Development Goals (MDGs) but with some major differences. On one hand, where MDGs were mainly focussed on poverty and hunger (largely of less developed countries), SDGs have 17 agendas covering around 169 targets and is applicable to all the countries and regions of the globe. The goals are much broader in their terms, extending to social and economic aspects of human society and their dimensions with natural environment, by putting sustainability at the centre. The two key features i.e. economic security and environmental sustainability have been mainly highlighted in the wide range of categories. There is no denying the fact that to achieve the SDGs by 2030 is an ambitious project and its success will definitely obviate various issues related to sustainability of life on earth. Several of the targets set in SDGs were to be achieved by 2020 , which means only a year to go. At this point of time it becomes important to review the scenario on what has been achieved and what is lacking.

In a very recent report by Global Sustainable Development Report (2019), UN Secretary-General António Guterres has stated, "Our world as we know it and the future we want are at risk. Despite considerable efforts these past 4 years, we are not on track to achieve the Sustainable Development Goals by 2030". A recent report on SDGs index based on the monitoring of Sustainable Development Solutions Network (SDSN) has revealed that no country is in line to achieve targets of 2030 and slowest progress has been

Naveen Kumar Arora

nkarora.bbau@gmail.com

1 Department of Environmental Science, School for Environmental Science, BBA University, Lucknow, UP, India

2 Department of Environmental Microbiology, BBA University, Lucknow, UP, India witnessed mainly on goals focussed on environment (Sachs et al. 2019). Only a very few countries (Sweden, Denmark and Finland) have achieved three quarters of the UN goals. Organization for Economic Co-operation and Development (OECD) which includes the best performers, also needs to do better in controlling climate change and sustainable consumption (https://www.bertelsmann-stiftung.de/en/topics/ latest-news/2019/june/long-in-words-but-short-on-actio n-un-sustainability-goals-are-threatened-to-fail/). In the same way, another report by Global Opportunity Project and United Nations Global Compact (UNGC) based on a publication of 2016 titled as "The Future of Spaceship Earth" explains that there would surely be improvements in some areas in some regions of the globe but overall most of the goals are in red in most of the areas of the planet and will definitely miss the targets. Among the targets, environmental issues lack the most and will nullify other achievements if not tackled on priority.

Goals $6,7,12,13,14$ and 15 are directly related to environmental sustainability. The targets in these goals are mainly linked to natural environment but are lagging far behind and seem impossible to achieve in due time frame. The aforementioned goals are devoted for clean water and sanitation, affordable and clean energy, sustainable consumption of natural resources, climate change, life below water and on terrestrial ecosystems, halting biodiversity loss and combating land degradation and desertification. Clean water and sanitation is the basic human right but alarmingly it has been denied to billions of people across the globe. World Water Development Report (2019) explains that since 1980, water consumption has been increasing at a rate of $1 \%$ per year and is expected to grow up to $3 \%$ by 2050 (https:// www.unwater.org/publications/world-water-developmen t-report-2019/). As per the analysis of Water Aid (2017), it was found that one in ten people still has no access to clean water and $31 \%$ lack basic sanitation facilities (https://washm atters.wateraid.org/sites/g/files/jkxoof256/files/How\%20 to $\% 20$ get $\% 20$ water $\% 20$ and $\% 20$ sanitation $\% 20$ to $\% 20$ eve 
ryone $\% 20$ by $\% 202030$.pdf). These reports clearly suggest that it is very unlikely that we will achieve the targets of Goal 6 by 2030 particularly if drastic corrective measures are not taken. Moreover, this will maintain high mortality rate among children, particularly in developing and poor regions of the world due to issues of hygiene and communicable diseases (https://www.wateraid.org/facts-and-statistics). On the other hand, World Bank (2018) reported that in case of affordable and sustainable energy, again the records show very dismal growth which makes it difficult to achieve the defined timeline of Goal 7. Around 13\% of global population ( $\sim$ billion) still lacks access to electricity and 674 million people will be living without electricity by 2030 . In same way, $40 \%$ people of the world (around 3 billion) lack clean fuel technologies (https://www.worldbank.org/en/news/press -release/2018/05/02/sustainable-development-goal-sdg-7global-progress-report). Fossil fuel consumption is touching its highest and accounted for $82 \%$ of total primary energy supply in 2015 (Boden et al. 2017). Our World in Data report states that global fossil fuel consumption (mainly includes natural gas, crude oil and coal) has almost doubled in last 20 years or so (https://ourworldindata.org/fossil-fuels). Goal 12 targets sustainable consumption and this is should not be a very difficult to achieve. But the way natural resources are being exploited, degraded, and polluted this target is going to be largely unachieved. As per estimates one-third of the food produced on the globe goes waste and on the other hand 800 million are malnourished and the disparity is increasing by the day. This is another major setback to the goal of sustainable consumption. Climate change is already accelerating at a rapid pace hampering the targets of Goal 13. Studies suggest that earth's climate has always been more or less unstable but current situation is mainly induced due to anthropogenic activities and is very fast in comparison to natural processes (Arora et al 2018). With rise in population and energy consumption, release of greenhouse gases (GHGs) is expected to increase to $50 \%$ by 2050 (https:// www.oecd.org/env/cc/49082173.pdf). According to report of UN World Meteorological Organization, if the latest trends of GHGs continue, average global temperature on earth is projected to spike up to $3-5{ }^{\circ} \mathrm{C}$ by 2100 . (https:// www.reuters.com/article/us-climate-change-un/globa 1-temperatures-on-track-for-3-5-degree-rise-by-2100-u-nidUSKCN1NY186). A global assessment report by International Energy Agency suggests that energy consumption has grown by $2.3 \%$ which is ten times faster than past 10 years resulting in $1.7 \%$ more carbon emissions (https://sdg.iisd. org/news/global-energy-demand-in-2018-grew-at-fastestpace-in-a-decade/). Adverse effects of human activities are also visible on below water and on terrestrial ecosystems. Threats like water pollution, aquaculture and overexploitation of ocean resources have resulted in huge loss of biodiversity in water bodies. World Wide Fund for Nature (WWF)
(2014) reported a decline in population of freshwater species by $76 \%$ between 1970 and 2010 which escalated to $83 \%$ between 1970 and 2014 (World Wide Fund for Nature 2018). Similarly, global inland wetlands have reduced by up to $71 \%$ and of them $89 \%$ are not secured (Bastin et al. 2019). Ecosystem services provided by water bodies cannot be fully assessed in terms of economics and capital gains as they play so many important roles in maintaining the ecological and climate balance on earth. But still, studies suggest that freshwater ecosystems provide services worth USD 4 trillion and these are in extreme danger of being wiped out due to various anthropogenic activities (Flitcroft et al. 2019). Similarly, oceans are facing dramatic transformation and are warming and acidifying at a very rapid rate driving significant climate change, and threatening marine biodiversity and ecosystem services. Reports claim that throughout the twentieth century, the average global sea level has doubled from $1.7 \mathrm{~mm}$ per year to $3.1 \mathrm{~mm} /$ year since 1993 and is projected to rise up to $0.2 \mathrm{~m}$ by 2100 mainly due to glacier and ice sheet melting, and thermal expansion of sea water (https://www.clima te.gov/news-features/understanding-climate/climate-chang e-global-sea-level). This will also result in soil erosion, terrestrial degradation and shrinkage of habitable and agricultural lands. These reports clearly seem to threaten the fulfilment of the objectives of Goal 14 which is about protection of life below water. Intergovernment Science-Policy Platform on Biodiversity and Ecosystem Services (IPBES) (2019) has compiled a report which suggests that around $25 \%$ of animal and plant species are threatened at present and over a million will be facing extinction within few decades which is ten times higher than the average rate since past 10 million years (https://www.un.org/sustainabledeve lopment/blog/2019/05/nature-decline-unprecedented-repor $t /$ ). In case of forest cover, although recent reports suggest that the rate of deforestation appears to be slowing down, but due to unplanned cutting of jungles in the past (and continuing in some parts even at present) the big forests are being fragmented, leading to several issues including biodiversity loss, climate change, increase in invading species and fragile ecosystems. However, there still is a continuous shrinkage in forest cover due to growing agricultural lands (in place of forests), fires and illegal mining. Recent fires in Amazon's rainforests, known as the lungs of the earth, is alarming. This 2.2 million square mile forest cover, which acts as a major sink to earth's carbon emissions, is at its tipping point and is nearing towards becoming a fragmented drier zone of ecosystem. WWF states that Amazon region has lost about $17 \%$ of its forest cover since last half century, mainly due to anthropogenic interference (https://www. worldwildlife.org/threats/deforestation-and-forest-degra dation). This will result in accelerated loss of innumerous species as well as higher rate of climate change, extreme weather events and air, water and land pollution. WWF 
report also reveals that accelerated habitat fragmentation as a result of human activities has narrowed the wildlife population to $53 \%$ since 1970 , with highest declines in tropical forests (https://www.worldwildlife.org/stories/forest-wildl ife-populations-decline-53-since-1970). Fragmented habitat not only causes species reduction but also brings about land degradation and soil erosion. A global assessment by United Nations Convention to Combat Desertification (UNCCD) states that tree cover areas have reduced by 35,204 sq km in last 15 years causing overall massive land desertification. In the same way, degradation of land has exacerbated and study reveals that $25 \%$ of the total land across the world has been degraded. In addition, each day we are losing around 24 billion tons of fertile soil due to aggravated rate of unsustainable practices (https://www.thegef.org/topics/land-degra dation). Apart from this, poaching and hunting have resulted in decline of species biodiversity. Air pollution, another global menace, has also considerably escalated affecting lives of millions across the world. WHO (2018) has reported that air pollution causes about 7 million deaths every year due to exposure to particulate matter and around $90 \%$ of world population breathe polluted air (https://www.ccaco alition.org/en/news/world-health-organization-releases-newglobal-air-pollution-data). A report by State of Global Air Report based on information of Global Burden of Disease (GBD) of 2017 mentioned that exposure to particulate matter was found highest in South Asia and second highest in western sub-Saharan Africa followed by countries of North Africa and Middle East. Together these issues have severely hampered the targets of Goal 15 and situation only seems to be worsening in near future.

The data from around the globe clearly shows that overall the situation is deteriorating particularly in concern to environmental sustainability. In fact, it will be not wrong to say that at present we are facing an environmental and climate emergency. It is important to take emergent steps towards successful implementation of targets and evidence based solutions at both micro and macro levels. Building of awareness through education should be encouraged and intensified to support sustainability agendas. Emerging role of media should also be utilized in this direction so that communication on sustainability related themes and schemes can be established at grassroots. Removing subsidies on fossil fuels and imposing taxes on high carbon footprint products can also help in raising awareness among people for lowering unprecedented use of such products. The carbon footprint i.e. carbon impact labelling should be marked on the product packages so that the individuals can themselves judge the ecological value of the product they are consuming. This policy should be implemented on food products as well. Consumption of food/produce involving low carbon footprint has to be encouraged. Government should support low carbon technologies and their implementation. Major carbon footprint impact is due to food production, energy/ fuel use, and transport. Hence focus should be on applying green technologies in these areas along with phasing out of polluting and GHGs emitting methods. Consumers also need to be made aware of carbon footprint for which they are responsible due to their lifestyle and shift to natural methods of living. Need is for complete overhaul of the human behavior towards environment. Governments around the globe need to work in synchrony to implement the policies related to SDGs. Subsidies on products causing harm to the environment should go. Instead taxes should be levied in proportion to the carbon footprint of the product. Apart from carbon taxes authorities and regulatory bodies also need to penalize the individuals or industries which indulge in damage to the ecosystems or causing huge carbon emissions. The tax collection should be utilized for improving or sustaining the ecosystems/environment and reducing the carbon footprint. Gross Domestic Product (GDP) is used to measure the economic progress of a country, similarly Gross Carbon Footprint (GCF) and Gross Sustainable Production (GSP) should be measured for assessing sustainable development (involving environment) for each country. In fact, there is an emerging debate on using GDP as the indicator of the development of the country, as it completely overlooks the environmental aspects. By measuring GCF and GSP the nation wise picture on sustainable development will become clearer. Hence GDP should be correlated with GCF and GSP to determine the correct scenario of sustainable development. In fact governments should go for sustainable investments rather than targeting short term benefits which are not good for future or the environment. Any venture, like development of infrastructure, should be evaluated for sustainability before investment. Implementation of policies related to sustainable development (particularly involving environment) need to be done by involving all the stakeholders including individuals, scientists, environmentalists, economists, governments, NGOs, international bodies and so on. Indigenous and local populations have to be involved for realizing the conservation of natural resources, diversity and adoption of sustainable technologies. Overall, the goals have to be considered cumulatively as all of them are interlinked. There is no point in achieving the targets in bits and pieces or fragments, which has what been done so far. Partial achievements in terms of regions/countries will be of little use at global level. Mankind has to achieve it together or otherwise will have to face the consequences in unison. Every nation needs to come together breaking the artificial boundaries in securing the environmental sustainability and viability of the blue planet.

The journal "Environmental Sustainability" will keep on projecting greener and ecofriendly technologies for saving and sustaining our environment and Society for Environmental Sustainability will also keep a closer watch on the 
developments around the globe, in relation to the Sustainable Development Goals.

\section{References}

Arora NK, Fatima T, Mishra I, Verma M, Mishra J, Mishra V (2018) Environmental sustainability: challenges and viable solutions. Environ Sustain 1(4):309-340

Bastin L, Gorelick N, Saura S, Bertzky B, Dubois G, Fortin MJ, Pekel JF (2019) Inland surface waters in protected areas globally: current coverage and 30-year trends. PLoS One 14:e0210496

Boden TA, Marland G, Andres RJ (2017) Global, regional, and national fossil-fuel CO2 emissions. Carbon Dioxide Information Analysis Center, Oak Ridge National Laboratory, US Department of Energy, Oak Ridge, Tenn. USA. http://cdiac.ess-dive.lbl.gov/trend s/emis/meth_reg.html
Flitcroft R, Cooperman MS, Harrison IJ, Juffe-Bignoli D, Boon PJ (2019) Theory and practice to conserve freshwater biodiversity in the Anthropocene. Aquat Conserv. https://doi.org/10.1002/aqc.3187

Independent Group of Scientists appointed by the Secretary-General, Global Sustainable Development Report (2019) The future is now-science for achieving sustainable development. United Nations, New York

Sachs J, Schmidt-Traub G, Kroll C, Lafortune G, Fuller G (2019) Sustainable development report 2019. Bertelsmann Stiftung and Sustainable Development Solutions Network (SDSN), New York

World Wide Fund for Nature (2014) Living planet report. In: McLellan $\mathrm{R}$, Iyenger L, Jeffries B, Oerlemans N (eds) Species and spaces, people and places. Gland, Gland WWF

World Wide Fund for Nature (2018) In: Grooten M, Almond REA (eds) Living planet report-2018: aiming higher. Gland WWF, Gland

Publisher's Note Springer Nature remains neutral with regard to jurisdictional claims in published maps and institutional affiliations. 